\title{
Prediction of Cancer Incidence and Mortality in Korea, 2012
}

\author{
Kyu-Won Jung, MS ${ }^{1}$ \\ Sohee Park, $\mathrm{PhD}^{1}$ \\ Young-Joo Won, $\mathrm{PhD}^{1}$ \\ Hyun-Joo Kong, MS' \\ Joo Young Lee, MD ${ }^{1}$ \\ Hong Gwan Seo, MD, PhD² \\ Jin-Soo Lee, MD, PhD ${ }^{1}$
}

\begin{abstract}
${ }^{1}$ The Korea Central Cancer Registry, Division of Cancer Registration and Surveillance, ${ }^{2}$ National Cancer Control Institute, National Cancer Center, Goyang, Korea
\end{abstract}

\begin{abstract}
Purpose
To estimate the current cancer burden in Korea, cancer incidence and mortality rates were projected for the year 2012.
\end{abstract}

\section{Materials and Methods}

The cancer incidence data from 1999 to 2009 were obtained from the Korea National Cancer Incidence Database, and the cancer mortality data from 1993 to 2010 were obtained from Statistics Korea. Cancer incidence in 2012 was projected by fitting a linear regression model on observed age-specific cancer incidence rates against observed years, then multiplying the projected agespecific rates by the age-specific population. For cancer mortality, a similar procedure was applied, except that a Joinpoint regression model was used to determine at which year the linear trend significantly changed.

\section{Results}

A total of 234,727 new cancer cases and 73,313 cancer deaths are projected to occur in Korea in 2012. For all sites combined, the crude incidence rates are projected to be 465.6 and 459.7, and the age-standardized incidences to be 345.1 and 300.9 per 100,000 respectively for males and females.

\section{Conclusion}

Cancer has become an important public health concern in Korea, and as the Korean population ages, the cancer burden will continue to increase.
Correspondence: Sohee Park, PhD

The Korea Central Cancer Registry,

Division of Cancer Registration and Surveillance,

National Cancer Center, 323 Ilsan-ro,

Ilsandong-gu, Goyang 410-769, Korea

Tel: 82-31-920-2015

Fax: 82-31-920-2179

E-mail: shpark@ncc.re.kr

Received March 2, 2012

Accepted March 5, 2012
Key words

Incidence, Mortality, Neoplasms, Prediction, Korea, 2012

\section{Introduction}

Since 1983, as the leading cause of death [1], cancer has become a major public health concern in Korea. Annually, over 190,000 patients are newly diagnosed with cancer in Korea, and one out of four deaths is due to cancer [2,3]. Although the cancer registration system in Korea is very efficient and can provide nationwide cancer statistics within a relatively short time, at least a 2-year lag is still required for accurate data collection and compilation. To plan and apply a cancer control program, it is important to assess the number of new cases and deaths that are expected to occur during the current year. In this report, we provide the projected cancer incidence and mortality ratio based on the data up to 2009.

\section{Materials and Methods}

The Korean Ministry of Health and Welfare initiated a nationwide, hos- 
pital-based cancer registry (the Korea Central Cancer Registry [KCCR]) in 1980. The details of the history, objectives, and activities of the KCCR have been documented elsewhere [4]. Incidence data from 1999 to 2009 were obtained from the Korea National Cancer Incidence Database (KNCI DB). Cancer cases were classified according to the International Classification of Diseases for Oncology, 3rd edition [5] and converted according to the International Classification of Diseases, 10 th edition (ICD10) [6].

Mortality data from 1993 to 2010 were obtained from Statistics Korea [1]. The cause of death was coded and classified according to ICD-10.

The cancer sites included in this report are (i) all cancers combined and (ii) the 22 most common cancers: lip, month, and pharynx (C00-C14), esophagus (C15), stomach (C16), colon and rectum (C18-C20), liver and intrahepatic bile duct (liver) (C22), gallbladder and other parts of biliary tract (gallbladder) (C23-C24), pancreas (C25), lung and bronchus (lung) (C33-C34), breast (C50), uterine cervix (C53), uterine corpus (C54), ovary (C56), prostate (C61), testis (C62), kidney (C64), bladder (C67), brain and central nervous system (C70-C72), thyroid (C73), Hodgkin lymphoma (C81), non-Hodgkin lymphoma (C82-C85, C96), multiple myeloma (C90), leukemia (C91-C95), and all others.

Population data were obtained from the resident registration population reported by Statistics Korea. The mid-year population on July 1 of the respective year was applied when computing the incidence and deaths.

Due to the time required for data collection and analysis, incidence and mortality data are available is usually 2-3 years behind the current year. As such, we projected the expected number of new cancer cases and deaths in Korea in the current year to provide an estimate of the current cancer burden.

Linear regression models [7] were used to assess the time trend and the projection of rates. Based on the observed cancer incidence data, a linear regression model was fitted to the age-specific rates by 5 -year age group against observed years. From the projected age-specific rates in 2012, the estimated number of cancer cases was calculated by multiplying the rates by 2012's projected age-specific population size. For thyroid and prostate cancer, which showed significant curvilinear trends, we used a square root transformation when fitting a linear regression model and converted the predicted values back to the original scale.

To estimate the number of cancer deaths in 2012, we first ran a Joinpoint regression model on the data for 1993-2010 to detect the year of significant changes in the trend of cancer mortality by sex and cancer site. A Joinpoint regression describes changes in data trends by connecting several different line segments on a log scale at "joinpoints." This analysis was performed using the Joinpoint software (version 3.3, http://srab.cancer.gov/joinpoint) from the Surveillance Research Program of the National Cancer Institute in the USA [8]. After identifying the year of significant trend changes using Joinpoint regression analysis, a simple linear regression model was fitted to the last line segment to estimate age-specific cancer mortality rates in 2012. Similar to the method used for the projection of cancer incidence, the number of new deaths was then projected by multiplying the age-specific cancer mortality rates by 2012's projected agespecific population.

We summarized the results using the crude rates (CRs) and age-standardized rates (ASRs) of cancer incidence and mortality. The ASRs were standardized using the World Health Organization (WHO) world standard population [9].

\section{Results}

\section{Incidence}

Table 1 presents the estimated number of new cancer cases and deaths during 2012 in Korea by sex and cancer site. It is projected that 234,727 cases of cancer incidence will occur in 2012.

Table 2 presents the estimated CRs and ASRs of cancer incidence in 2012 by sex and cancer site. The CRs of all sites combined in males and females respectively in 2012 are projected to be 465.6 and 459.7 per 100,000 , and the ASRs of all sites combined are projected to be 345.1 and

\begin{tabular}{|c|c|c|c|}
\hline & & $\begin{array}{c}\text { Males } \\
118,304\end{array}$ & $\begin{array}{c}\text { Females } \\
116,423\end{array}$ \\
\hline & $(\%)$ & & $|\%|$ \\
\hline Stomach & 18.6 & & 33.4 \\
\hline Colon and rectum & 16.6 & & 14.1 \\
\hline Lung & 13.5 & & 10.8 \\
\hline Liver & 10.6 & & 8.9 \\
\hline Prostate & 9.3 & & 5.8 \\
\hline Thyroid & 6.1 & & 3.7 \\
\hline Bladder & 2.7 & & 2.8 \\
\hline Kidney & 2.5 & & 2.4 \\
\hline Pancreas & 2.5 & & 2.1 \\
\hline Gallbladder etc. & 2.3 & & 1.8 \\
\hline All sites & 100.0 & & 100.0 \\
\hline
\end{tabular}

A

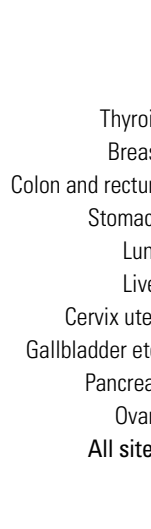

B

\begin{tabular}{|c|c|c|c|}
\hline & & $\begin{array}{l}\text { Males } \\
45,356\end{array}$ & $\begin{array}{c}\text { Females } \\
27,957\end{array}$ \\
\hline & $(\%)$ & & $(\%)$ \\
\hline Lung & 26.1 & & 15.6 \\
\hline Liver & 18.0 & & 12.7 \\
\hline Stomach & 12.4 & & 10.9 \\
\hline Colon and rectum & 10.2 & & 10.0 \\
\hline Pancreas & 5.4 & & 7.9 \\
\hline Gallbladder etc. & 4.1 & & 7.6 \\
\hline Prostate & 3.4 & & 7.2 \\
\hline Esophagus & 2.5 & & 3.5 \\
\hline Leukemia & 2.1 & & 2.9 \\
\hline Non-Hodgkin lymphoma & 1.9 & & 2.5 \\
\hline All sites & 100.0 & & 100.0 \\
\hline
\end{tabular}

$\begin{array}{rr}(\%) & \\ 5.6 & \text { Lung } \\ 2.7 & \text { Colon and rectum } \\ 0.9 & \text { Stomach } \\ 0.0 & \text { Liver } \\ 7.9 & \text { Pancreas } \\ 7.6 & \text { Breast } \\ 7.2 & \text { Gallbladder etc. } \\ 3.5 & \text { Ovary } \\ 2.9 & \text { Cervix uteri } \\ 2.5 & \text { Leukemia } \\ 0.0 & \text { All sites }\end{array}$

Fig. 1. The 10 leading types of estimated new cancer cases and deaths by gender in 2012. (A) Estimated new cases. (B) Estimated deaths. 
Table 1. Estimated new cancer cases and deaths by gender during 2012 in Korea

\begin{tabular}{|c|c|c|c|c|c|c|}
\hline \multirow{2}{*}{ Sites } & \multicolumn{3}{|c|}{ Estimated new cases } & \multicolumn{3}{|c|}{ Estimated deaths } \\
\hline & Both genders & Male & Female & Both genders & Male & Female \\
\hline All sites & 234,727 & 118,304 & 116,423 & 73,313 & 45,356 & 27,957 \\
\hline Lip, oral cavity, and pharynx & 2,801 & 2,102 & 699 & 1,024 & 754 & 270 \\
\hline Esophagus & 2,262 & 2,075 & 187 & 1,223 & 1,139 & 84 \\
\hline Stomach & 32,455 & 22,054 & 10,401 & 8,685 & 5,630 & 3,055 \\
\hline Colon and rectum & 32,215 & 19,669 & 12,546 & 8,195 & 4,648 & 3,547 \\
\hline Liver & 16,910 & 12,585 & 4,325 & 10,973 & 8,186 & 2,787 \\
\hline Gallbladder ${ }^{a)}$ & 5,481 & 2,697 & 2,784 & 3,884 & 1,879 & 2,005 \\
\hline Pancreas & 5,396 & 2,911 & 2,485 & 4,663 & 2,445 & 2,218 \\
\hline Larynx & 1,077 & 1,036 & 41 & 226 & 210 & 16 \\
\hline Lung & 22,737 & 15,991 & 6,746 & 16,168 & 11,819 & 4,349 \\
\hline Breast & 16,436 & 63 & 16,373 & 2,146 & 16 & 2,130 \\
\hline Cervix uteri & 3,292 & - & 3,292 & 819 & - & 19 \\
\hline Corpus uteri & 2,085 & - & 2,085 & 259 & - & 259 \\
\hline Ovary & 2,124 & - & 2,124 & 987 & - & 987 \\
\hline Prostate & 11,016 & 11,016 & - & 1,540 & 1,540 & - \\
\hline Testis & 215 & 215 & - & 18 & 18 & - \\
\hline Kidney & 4,310 & 2,949 & 1,361 & 846 & 558 & 288 \\
\hline Bladder & 3,969 & 3,185 & 784 & 1,026 & 737 & 289 \\
\hline Brain and CNS & 1,837 & 975 & 862 & 1,061 & 575 & 486 \\
\hline Thyroid & 46,021 & 7,158 & 38,863 & 360 & 100 & 260 \\
\hline Hodgkin lymphoma & 253 & 160 & 93 & 41 & 26 & 15 \\
\hline Non-Hodgkin lymphoma & 4,506 & 2,502 & 2,004 & 1,493 & 865 & 628 \\
\hline Multiple myeloma & 1,236 & 648 & 588 & 841 & 424 & 417 \\
\hline Leukemia & 2,885 & 1,609 & 1,276 & 1,676 & 964 & 712 \\
\hline Other and ill defined & 13,208 & 6,704 & 6,504 & 5,159 & 2,823 & 2,336 \\
\hline
\end{tabular}

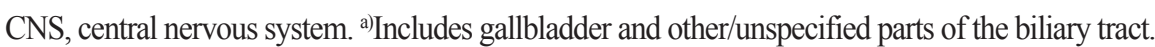

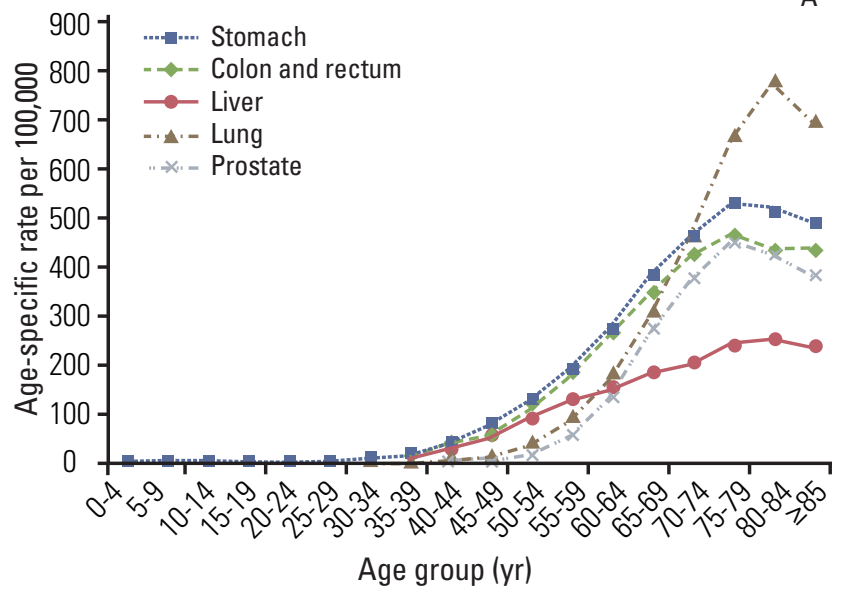

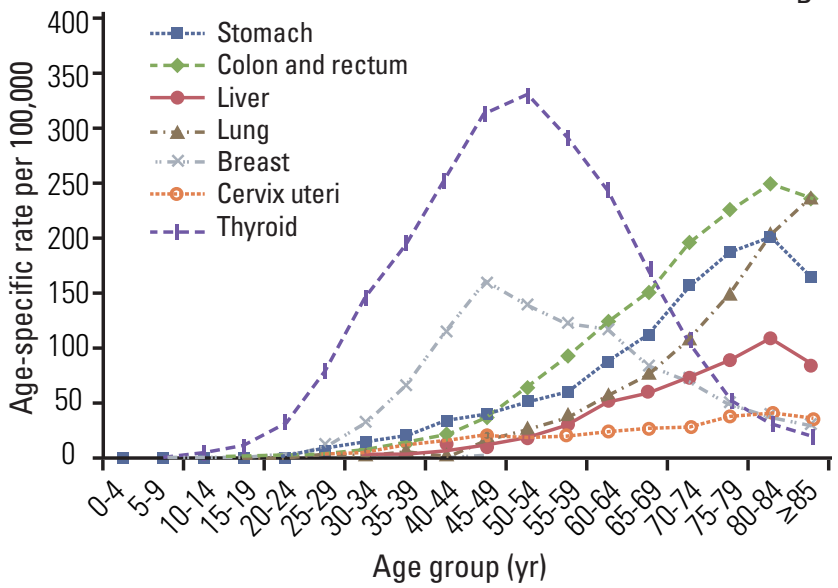

Fig. 2. Projected age-specific incidences of major cancers during 2012 in Korea. (A) Male. (B) Female.

300.9 per 100,000. In males, the five leading primary sites of cancer are expected to be the stomach (CR, 86.8; ASR, 63.2), colon and rectum (CR, 77.4;ASR, 56.7), lung (CR, 62.9; ASR, 46.6), liver (CR, 49.5; ASR, 35.6), and prostate (CR, 43.4; ASR, 32.5), accounting for $68.7 \%$ of all newly diagnosed cancers in 2012. In females, the most common cancer sites are expected to be thyroid (CR, 153.4; ASR, 109.4), breast (CR, 64.6; ASR, 44.1), colon and rectum (CR, 49.5; ASR, 29.5), stomach (CR, 41.1; ASR, 24.7), lung (CR, 26.6; ASR, 14.7), and liver (CR, 17.1; ASR, 10.0), ac- 
Table 2. Estimated crude and age-standardized cancer incidences by gender during 2012 in Korea

\begin{tabular}{|c|c|c|c|c|c|c|}
\hline & \multicolumn{3}{|c|}{ Crude incidence rates $/ \mathbf{1 0 0 , 0 0 0}$} & \multicolumn{3}{|c|}{ Age-standardized incidence rates $/ 100,000^{\mathrm{a}}$} \\
\hline & Both genders & Male & Female & Both genders & Male & Female \\
\hline All sites & 462.7 & 465.6 & 459.7 & 312.5 & 345.1 & 300.9 \\
\hline Lip, oral cavity, and pharynx & 5.5 & 8.3 & 2.8 & 3.8 & 6.0 & 1.9 \\
\hline Esophagus & 4.5 & 8.2 & 0.7 & 2.9 & 6.1 & 0.4 \\
\hline Stomach & 64.0 & 86.8 & 41.1 & 42.1 & 63.2 & 24.7 \\
\hline Colon and rectum & 63.5 & 77.4 & 49.5 & 41.9 & 56.7 & 29.5 \\
\hline Liver & 33.3 & 49.5 & 17.1 & 22.0 & 35.6 & 10.0 \\
\hline Gallbladder ${ }^{\mathrm{b})}$ & 10.8 & 10.6 & 11.0 & 6.7 & 7.9 & 5.7 \\
\hline Pancreas & 10.6 & 11.5 & 9.8 & 6.7 & 8.4 & 5.3 \\
\hline Larynx & 2.1 & 4.1 & 0.2 & 1.4 & 3.0 & 0.1 \\
\hline Lung & 44.8 & 62.9 & 26.6 & 28.2 & 46.6 & 14.7 \\
\hline Breast & 32.4 & 0.2 & 64.6 & 22.2 & 0.2 & 44.1 \\
\hline Cervix uteri & 6.5 & - & 13.0 & 4.4 & - & 8.5 \\
\hline Corpus uteri & 4.1 & - & 8.2 & 2.8 & - & 5.5 \\
\hline Ovary & 4.2 & - & 8.4 & 3.0 & - & 5.8 \\
\hline Prostate & 21.7 & 43.4 & - & 14.1 & 32.5 & - \\
\hline Testis & 0.4 & 0.8 & - & 0.4 & 0.8 & - \\
\hline Kidney & 8.5 & 11.6 & 5.4 & 5.9 & 8.5 & 3.5 \\
\hline Bladder & 7.8 & 12.5 & 3.1 & 4.9 & 9.2 & 1.6 \\
\hline Brain and CNS & 3.6 & 3.8 & 3.4 & 3.1 & 3.4 & 2.7 \\
\hline Thyroid & 90.7 & 28.2 & 153.4 & 64.5 & 20.1 & 109.4 \\
\hline Hodgkin lymphoma & 0.5 & 0.6 & 0.4 & 0.4 & 0.5 & 0.3 \\
\hline Non-Hodgkin lymphoma & 8.9 & 9.8 & 7.9 & 6.4 & 7.7 & 5.4 \\
\hline Multiple myeloma & 2.4 & 2.6 & 2.3 & 1.6 & 1.9 & 1.4 \\
\hline Leukemia & 5.7 & 6.3 & 5.0 & 5.1 & 6.0 & 4.4 \\
\hline Other and ill defined & 26.0 & 26.4 & 25.7 & 18.1 & 20.7 & 15.9 \\
\hline
\end{tabular}

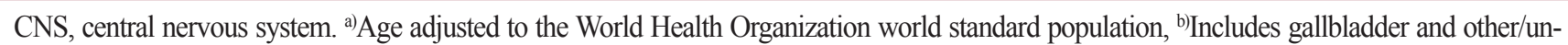
specified parts of biliary tract.
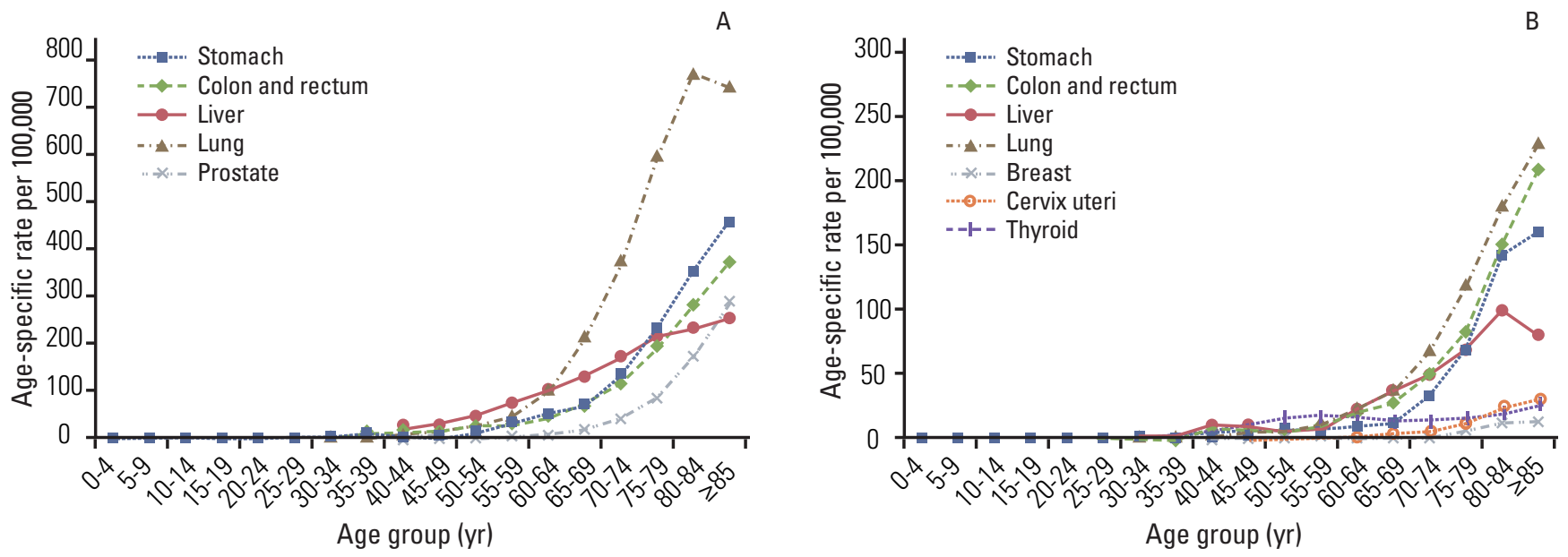

Fig. 3. Projected age-specific mortality rates of major cancers during 2012 in Korea. (A) Male. (B) Female.

counting for $76.7 \%$ of all newly diagnosed cancers (Fig. 1). Thyroid cancer alone is projected to account for $33.4 \%$ (38,863 cases) of incident cases in females in 2012.
Table 3 presents the most common cancer sites expected in 2012 by sex and age group. Leukemia and thyroid cancer are projected to be the most common forms of cancer in both sexes for the 0-14 and 15-34 age 
Table 3. Estimated cancer incidence by age group and sex during 2012 in Korea

\begin{tabular}{|c|c|c|c|c|}
\hline \multirow{2}{*}{ Rank } & \multicolumn{4}{|c|}{ Age group (yr) } \\
\hline & $0-14$ & $15-34$ & $35-64$ & $\geq 65$ \\
\hline \multicolumn{5}{|l|}{ Male } \\
\hline 1 & $\begin{array}{l}\text { Leukemia } \\
\text { (4.9) }\end{array}$ & $\begin{array}{l}\text { Thyroid } \\
(12.2)\end{array}$ & $\begin{array}{c}\text { Stomach } \\
(98.2)\end{array}$ & $\begin{array}{l}\text { Lung } \\
(479.0)\end{array}$ \\
\hline 2 & $\begin{array}{c}\text { Brain and CNS } \\
(2.4)\end{array}$ & $\begin{array}{l}\text { Leukemia } \\
\quad(3.2)\end{array}$ & $\begin{array}{c}\text { Colon and rectum } \\
\text { (86.6) }\end{array}$ & $\begin{array}{c}\text { Stomach } \\
(449.8)\end{array}$ \\
\hline 3 & $\begin{array}{c}\text { Non-Hodgkin lymphoma } \\
\text { (1.8) }\end{array}$ & $\begin{array}{c}\text { Non-Hodgkin lymphoma } \\
\text { (2.9) }\end{array}$ & $\begin{array}{l}\text { Liver } \\
(65.9)\end{array}$ & $\begin{array}{c}\text { Colon and rectum } \\
(404.0)\end{array}$ \\
\hline 4 & $\begin{array}{c}\text { Kidney } \\
(0.5)\end{array}$ & $\begin{array}{c}\text { Colon and rectum } \\
(2.8)\end{array}$ & $\begin{array}{c}\text { Thyroid } \\
(47.9)\end{array}$ & $\begin{array}{l}\text { Prostate } \\
(350.5)\end{array}$ \\
\hline 5 & $\begin{array}{l}\text { Testis } \\
(0.4)\end{array}$ & $\begin{array}{c}\text { Stomach } \\
(2.5)\end{array}$ & $\begin{array}{l}\text { Lung } \\
(41.3)\end{array}$ & $\begin{array}{l}\text { Liver } \\
(207.2)\end{array}$ \\
\hline \multicolumn{5}{|l|}{ Female } \\
\hline 1 & $\begin{array}{l}\text { Leukemia } \\
\qquad(4.0)\end{array}$ & $\begin{array}{l}\text { Thyroid } \\
(68.5)\end{array}$ & $\begin{array}{l}\text { Thyroid } \\
(272.4)\end{array}$ & $\begin{array}{c}\text { Colon and rectum } \\
\text { (198.8) }\end{array}$ \\
\hline 2 & $\begin{array}{c}\text { Brain and CNS } \\
(2.0)\end{array}$ & $\begin{array}{l}\text { Breast } \\
(11.2)\end{array}$ & $\begin{array}{l}\text { Breast } \\
(119.4)\end{array}$ & $\begin{array}{l}\text { Stomach } \\
(154.9)\end{array}$ \\
\hline 3 & $\begin{array}{l}\text { Non-Hodgkin lymphoma } \\
\text { (1.0) }\end{array}$ & $\begin{array}{c}\text { Cervix uteri } \\
\text { (4.9) }\end{array}$ & $\begin{array}{c}\text { Colon and rectum } \\
\text { (49.9) }\end{array}$ & $\begin{array}{c}\text { Lung } \\
\text { (129.8) }\end{array}$ \\
\hline 4 & $\begin{array}{c}\text { Ovary } \\
(0.7)\end{array}$ & $\begin{array}{c}\text { Stomach } \\
(4.3)\end{array}$ & $\begin{array}{c}\text { Stomach } \\
(43.1)\end{array}$ & $\begin{array}{c}\text { Thyroid } \\
(96.5)\end{array}$ \\
\hline 5 & $\begin{array}{l}\text { Kidney } \\
(0.5)\end{array}$ & $\begin{array}{c}\text { Colon and rectum } \\
\text { (2.7) }\end{array}$ & $\begin{array}{l}\text { Lung } \\
\text { (20.6) }\end{array}$ & $\begin{array}{l}\text { Liver } \\
(76.7)\end{array}$ \\
\hline
\end{tabular}

CNS, central nervous system.

groups. Gastric cancer is predicted to be the most common cancer in males 35-64 years of age, whereas lung cancer is predicted to be more frequent for malese $\geq 65$ years of age. Thyroid cancer is predicted to be the most common cancer for females 35-64 years of age, whereas colorectal cancer is predicted to be the most common cancer for females $\geq 65$ years of age. Fig. 2 shows the age-specific incidence rates of the selected cancers for men and women in 2012. The projection indicates that the incidence of gastric, lung, liver, and colorectal cancers will increase gradually with age. In women, the age-specific incidence rates of breast and thyroid cancer will increase with age until the 5th and 6th decades of life, and then level off.

\section{Mortality}

It is estimated that 73,313 cancer deaths will occur in Korea during 2012 (Table 1). The CRs of all sites combined in 2012 respectively for males and females are projected to be 178.5 and 110.4 per 100,000, and the ASRs of all sites combined are expected to be 135.8 and 59.0 per 100,000 (Table 4).

In 2012, the five leading cancer sites causing mortality in males are predicted to be lung (CR, 46.5; ASR, 34.4), liver (CR, 32.2; ASR, 23.5), stomach (CR, 22.2; ASR, 16.4), colon and rectum (CR, 18.3; ASR, 13.7), and pancreas (CR, 9.6; ASR, 7.1). During the same time period, in fe- males, lung cancer (CR, 17.2; ASR, 8.7) is projected to be the leading cancer site causing mortality, followed by cancers of the colon and rectum (CR, 14.0; ASR, 7.1), stomach (CR, 12.1; ASR, 6.1), liver (CR, 11.0; ASR, 6.0), and pancreas (CR, 8.8; ASR, 4.5).

Fig. 3 shows the age-specific predicted mortality rates of the selected cancers for males and females in 2012 . When examined by age, Korean males $>60$ years of age are expected to have the highest mortality rates from liver cancer, followed by lung cancer. In contrast, Korean females $>$ 55 years of age are expected to have the highest mortality rates from breast cancer, followed by lung cancer.

\section{Conclusion}

This report provides the estimated nationwide cancer incidence and mortality in Korea for the current year. A total of 234,727 new cancer cases and 73,313 cancer deaths are expected in Korea during 2012. In Korean males, gastric, colorectal, lung, liver, and prostate cancers are estimated to have the highest rates of incidence, while lung, liver, gastric, colorectal, and pancreatic cancers are estimated to be the most common causes of cancer-related deaths. In Korean females, thyroid, breast, colorectal, gastric, and lung cancer are estimated to have the highest rates of 
Table 4. Estimated crude and age-standardized cancer mortality rates by gender during 2012 in Korea

\begin{tabular}{|c|c|c|c|c|c|c|}
\hline \multirow{2}{*}{ Sites } & \multicolumn{3}{|c|}{ Crude incidence rates/100,000 } & \multicolumn{3}{|c|}{ Age-standardized incidence rates $/ \mathbf{1 0 0 , 0 0 0 ^ { a } )}$} \\
\hline & Both genders & Male & Female & Both genders & Male & Female \\
\hline All sites & 144.5 & 178.5 & 110.4 & 89.7 & 132.8 & 59.0 \\
\hline Lip, oral cavity, and pharynx & 2.0 & 3.0 & 1.1 & 1.3 & 2.1 & 0.6 \\
\hline Esophagus & 2.4 & 4.5 & 0.3 & 1.5 & 3.3 & 0.1 \\
\hline Stomach & 17.1 & 22.2 & 12.1 & 10.4 & 16.4 & 6.1 \\
\hline Colon and rectum & 16.2 & 18.3 & 14.0 & 9.8 & 13.7 & 7.1 \\
\hline Liver & 21.6 & 32.2 & 11.0 & 14.0 & 23.5 & 6.0 \\
\hline Gallbladder $^{\text {b) }}$ & 7.7 & 7.4 & 7.9 & 4.5 & 5.5 & 3.8 \\
\hline Pancreas & 9.2 & 9.6 & 8.8 & 5.7 & 7.1 & 4.5 \\
\hline Larynx & 0.4 & 0.8 & 0.1 & 0.3 & 0.6 & 0.0 \\
\hline Lung & 31.9 & 46.5 & 17.2 & 19.3 & 34.4 & 8.7 \\
\hline Breast & 4.2 & 0.1 & 8.4 & 2.8 & 0.0 & 5.4 \\
\hline Cervix uteri & 1.6 & - & 3.2 & 1.0 & - & 1.8 \\
\hline Corpus uteri & 0.5 & - & 1.0 & 0.3 & - & 0.6 \\
\hline Ovary & 1.9 & - & 3.9 & 1.2 & - & 2.3 \\
\hline Prostate & 3.0 & 6.1 & - & 1.7 & 4.7 & - \\
\hline Testis & 0.0 & 0.1 & - & 0.0 & 0.1 & - \\
\hline Kidney & 1.7 & 2.2 & 1.1 & 1.0 & 1.6 & 0.6 \\
\hline Bladder & 2.0 & 2.9 & 1.1 & 1.1 & 2.2 & 0.5 \\
\hline Brain and CNS & 2.1 & 2.3 & 1.9 & 1.5 & 1.8 & 1.3 \\
\hline Thyroid & 0.7 & 0.4 & 1.0 & 0.4 & 0.3 & 0.5 \\
\hline Hodgkin lymphoma & 0.1 & 0.1 & 0.1 & 0.1 & 0.1 & 0.0 \\
\hline Non-Hodgkin lymphoma & 2.9 & 3.4 & 2.5 & 1.9 & 2.6 & 1.3 \\
\hline Multiple myeloma & 1.7 & 1.7 & 1.6 & 1.0 & 1.2 & 0.9 \\
\hline Leukemia & 3.3 & 3.8 & 2.8 & 2.4 & 3.0 & 1.9 \\
\hline Other and ill defined & 10.2 & 11.1 & 9.2 & 6.4 & 8.4 & 5.0 \\
\hline
\end{tabular}

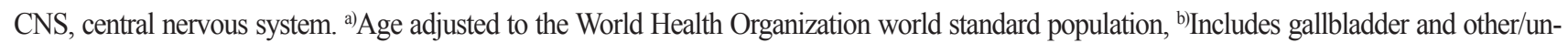
specified parts of biliary tract.

incidence, while lung, colorectal, stomach, liver, and pancreas cancers are estimated to be the most common causes of cancer-related deaths.

Cancer has become an important public health concern in Korea, and as the population continues to age, the cancer burden will continue to increase. The estimated cancer statistics of the current year given in this report represent an important resource to plan and evaluate cancer-control programs. The estimates in this report, however, are projected numbers based on statistical models and may vary from year to year; hence, these estimates should be used with caution.

\section{References}

1. Statistics Korea, 2012 [Internet]. Daejeon: Statistics Korea; 2012 [cited 2012 Jan 14]. Available from: http://kostat.go.kr.

2. Ministry of Health and Welfare. 2009 annual report of cancer statistics in Korea. Seoul: Ministry

\section{Conflicts of Interest}

Conflict of interest relevant to this article was not reported.

\section{Acknowledgments}

This work was supported by a research grant from the National Cancer Center (No. 1010160) and National Health Promotion Program grants (Nos. 1160390 and 1160400) from the Ministry of Health and Welfare, Republic of Korea. 
4. Shin HR, Won YJ, Jung KW, Kong HJ, Yim SH, Lee JK, et al. Nationwide cancer incidence in Korea, 1999 2001: first result using the national cancer incidence database. Cancer Res Treat. 2005;37:325-31

5. Fritz A, Percy C, Jack A, Shanmugaratnam K, Sobin L, Parkin DM, et al. International classification of diseases for oncology. 3rd ed. Geneva: World Health Organization; 2000.

6. World Health Organization. Manual of the international statistical classification of diseases, injuries, and causes of death. 10th rev. Geneva: World Health Organization; 1992.

7. Boyle P, Parkin DM. Statistical methods for registries. In: Jensen OM, Parkin DM,
MacLennnan R, Muir CS, Skeet RG, editors. Cancer registration: principles and methods. IARC Scientific Publication No. 95. Lyon: IARC; 1991. p. 126-58.

8. National Cancer Institute. Joinpoint Regression Program, version 3.3 [Internet]. Bethesda, MD: National Cancer Institute; 2012 [cited 2012 Jan 6]. Available from: http://srab.cancer.gov/ joinpoint/.

9. Segi M. Cancer Mortality for selected sites in 24 countries (1950-1957). Sendai: Tohoku University School of Medicine; 1960. 